\title{
Protesters' Reactions to Video Surveillance of Article Demonstrations: Counter-Moves, Security Cultures, and the Spiral of Surveillance and Counter-Surveillance
}

\section{Peter Ullrich}

Technische Universität Berlin, Germany

ullrich@ztg.tu-berlin.de

\author{
Philipp Knopp \\ Technische Universität Berlin, Germany \\ knopp@ztg.tu-berlin.de
}

\begin{abstract}
This article analyses protesters' reactions to police video surveillance of demonstrations in Germany. Theoretically, we draw on the concept of a "spiral of surveillance and counter-surveillance" to understand the interaction processes which-intentionally or not-contribute to the deepening of the "surveillant assemblage" in the field of protest policing. After introducing video surveillance and its importance for selective protest policing, we discuss concepts of counter-surveillance. Widening the individualist scope of former research on "neutralisation techniques," collective and interactive dimensions are added to cover the full counter-surveillance repertoire. We identified six basic categories of counter-surveillance moves: consider cameras, disguise, attack, hide, sousveillance, and cooperation. They can be classified along the axes of (a) degree of cooperation with the police, and (b) directedness (inwards/outward). It becomes obvious that activists are not predominantly deterred by video surveillance but adapt to the situation. If and how certain counter-surveillance moves are applied depends on the degree of exposure, perceptions of conflict dynamics, political interpretations, and on how these factors are processed in the respective security cultures. Security cultures, which are grounded in the respective relations between protest groups and police, are collective sets of practices and interpretive patterns aimed at securing safety and/or anonymity of activists as well as making their claims visible. Thus, they are productive power effects, resulting from the very conditions under which protest takes place in contemporary surveillance societies. This article elaborates on these ambiguities and unintended effects with regard to sousveillance and disguise techniques, such as masking or uniform clothing. The analysis is based on qualitative data collected between 2011 and 2016 consisting of group discussions and interviews with activists from different political spectra, journalists, politicians, and police officers, as well as observations of demonstrations and document analyses of movement literature.
\end{abstract}

\section{The Problem}

About ten helmeted riot policemen lead a detained protester to a police car. One officer films the crowd of protesters following the police and their detained co-protester. One protester in turn films the police with his mobile loudly lamenting the behaviour of the police. The camera officer calmly keeps on videotaping until the police drive away with the detained (field protocol 077).

This protest scene in Berlin could take place countless times at demonstrations all over the world. At first glance, we might observe a symmetry of visual power, which results in a relatively peaceful solution to a highly emotional, conflictive situation. This article discusses the very hopes for an 'equality of arms' in

Ullrich, Peter, and Philipp Knopp. 2018. Protesters' Reactions to Video Surveillance of Demonstrations: Counter-Moves, Security Cultures, and the Spiral of Surveillance and Counter-Surveillance. Surveillance \& Society 16(2): 183-202. 
demonstrations through counter-surveillance and the fragility and contradictions of such situations in the contemporary "surveillant assemblage" (Haggerty and Ericson 2000).

While surveillance of political activism has been a salient issue in protest research and surveillance studies, video surveillance, an integral part of the policing of demonstrations in many Western countries, has not received close enough attention (Ullrich and Wollinger 2011) - quite unlike its 'big brother' stationary CCTV, which has defined the core issues of surveillance studies for some time. Camera use for watching and recording protesters has, of course, been acknowledged as a part of current policing styles, for which information gathering is a main pillar (Wood 2014). However, we know little about protester reactions to video surveillance, although critical discourse and, not least, several court rulings have speculated about the cameras' deterring effects. There are exploratory studies which suggest that the spectrum of activist reactions is indeed much wider (section 2), but there is still a lacuna in systematic analyses.

To fill this gap, we analysed interviews and group discussions with protesters and riot police as well as observation data from Germany. We analysed the plethora of activists' practices with which they reacted to video surveillance, in other words: we focus on their agency (section 4.1). In previous research, this has often been labelled - without covering the full spectrum of options - with concepts such as "neutralization techniques," "sousveillance," or "counter-surveillance," the "intentional, tactical uses, or disruptions of surveillance technologies to challenge institutional power asymmetries" (Monahan 2006: 516). Gary T. Marx (2003) undertook an important "beginning effort" (374) of classifying several such behavioural moves functioning within and against "the new surveillance." Yet his micro-sociological approach comes with some restrictions. In order to be more precise, we will sharpen Marx's idea and apply it to a more specific setting (that of video surveillance in protest policing) while at the same time expanding the scope of possible reactions covered: researching the field of protest movements necessarily implies focusing on individual and collective agency. This includes not only shared practices in the sense of similar reactions of different persons to the same stimulus (see Marx 2003: 372) but emergent phenomena such as norms and genuinely collective practices in movement cultures (see Ullrich, Daphi, and Baumgarten 2014: 1213). We also aim at contextualising activists' actions and at showing how the increasing scale of video surveillance in protest policing has contributed to profound changes in protest practices. The practices responding to video surveillance are part and parcel to evolving security cultures (section 4.2.), which develop within general movement-sector-specific cultures of protest and are intended to maintain political agency as well as protesters' anonymity and safety.

Besides a first overview of the several neutralisation techniques, Marx (2003) makes another important, yet unsubstantiated claim. He stresses that neutralisation-moves are not restricted to one side, but the involved parties constitute an "adversarial social dance" (388) of moves and counter-moves. We will therefore also analyse the interrelations between protest practices and police practices, to show how neutralisation techniques (although unintentionally) contribute to a "spiral of surveillance and countersurveillance" (Wilson and Serisier 2010: 170) (section 4.3.) and thereby even aggravate the "disappearance of disappearance" (Haggerty and Ericson 2000: 619).

\section{Background and Theory}

\section{1 Selective Protest Policing and Video Surveillance: The German Case}

In Germany, the use of video surveillance for protest policing dates back to the 1960s (Kammerer 2011) but was not regulated until the 1989 reform of the federal assembly law (Ullrich and Wollinger 2011). Since then several cases in which police did not comply with the encroachment thresholds for video 
surveillance ended up in court. ${ }^{1}$ Despite the restrictive legislation, police seem to hold "nearly endless discretionary powers" (Backes, Dollase, and Heitmeyer 1998: 5, our translation; cf. Feest and Blankenburg 1972) in their decision to film. The factual or sociological discretion (Brusten 1971: 34; Skolnick 1966: 71ff.), which is much broader than the legal margins of discretion, encompasses decisions over the mere presence of cameras, choices about what is recorded and/or stored as well as the interpretation and manipulation of video footage. This process of subsequent objectifications constitutes the definitional power chain of the police (Ullrich 2018b), which is eyed with suspicion by many activists affected.

The introduction and use of monitoring technologies is part of a wider development towards the growing use of technology, and the informatisation and medialisation of protest policing (see Gillham and Noakes 2007; Wood 2014). Video surveillance also plays an important role in today's selective protest policing styles (della Porta and Reiter 1998), as it allows (Ullrich 2018b):

a) managing protests from a distance through the transmission of overview shots,

b) preventing breaches of the law,

c) identifying so-called disturbers and supplying strong evidence for breaches of the law, which increases the likelihood of charges being pressed,

d) postponing the moment of arrest (to avoid conflicts during the demonstrations), and

e) using footage for a specific framing of protests before courts and in the media.

In Germany, selective protest policing has been stipulated by the "Brokdorf-Beschluss," a Constitutional Court ruling that obliges police to only intervene against so-called disturbers while nevertheless having to facilitate the right to assembly for 'peaceful protesters.' This approach is also substantiated by current social-psychological models of protest policing (Reicher et al. 2007; Rikspolisstyrelsen 2013; Schreiber 2011; Stott 2009). To meet the requirements, several tactical adaptions were introduced such as threat categories for protesters, liaison officers, and last but not least special camera-equipped police units, some especially designed for hit-and-run-arrests in crowds.

\subsection{Counter-Surveillance: Agency within the Surveillance Assemblage}

Exploratory studies from different countries have shown that police videotaping is subject to a range of reactions by activists, from spontaneous resistance to highly elaborate technical efforts. ${ }^{2}$ Especially the ubiquity of smartphones has increased hopes of balancing police powers with videos 'from below' that tell the stories from the protesters" point of view. This type of "citizen journalism" (Allan and Thorsen 2009) is expected to increase police visibility (Goldsmith 2010) and their accountability through its potential to scandalise misconduct (Eijkman 2011). Such "sousveillance" (Mann, Nolan, and Wellman 2003) has to be seen in a broader context of diverse modes of critically engaging with surveillance, be it individual behaviour (Marx 2003) or counter-conduct (Death 2010), particular political interventions (Daphi, Lê, and Ullrich 2013; Monahan 2006; Wilson and Serisier 2010) or critical "artveillance" (Brighenti 2009; Galdon Clavell 2014). Yet, what is lacking is a systematisation of different moves and techniques in reaction to video surveillance and an analysis of their respective conditions.

\footnotetext{
${ }^{1}$ Courts interpreted the extensive use of police cameras as an interference with the constitutional right to assemble freely, reasoning that surveillance might scare citizens away from expressing dissent. Thus, nowadays German assembly laws only permit video surveillance and (the temporarily restricted) storage of these videos if there is factual evidence that public order or security is threatened by protesters.

2 e.g., in Australia (Wilson and Serisier 2010), Austria (Knopp and Ullrich 2016), Denmark (Neumayer and Stald 2014), Germany (Tuma 2017; Ullrich 2014; Ullrich and Wollinger 2011), Poland (von Brackel 2012), Spain (Hermida and Hernández-Santaolalla 2017), and several Asian countries (Andén-Papadopoulos 2014).
} 
Hence, protesters like members of society at large who are affected by surveillance, are not passive objects to the means of power. Cameras are a part of the overall protest experience and cannot be singled out as an isolated causal factor. They are rather interpreted in the light of movement-specific security cultures (Knopp and Ullrich submitted). Cameras stimulate interpretations and reflections in this context, i.e., they exert subtle, subjectifying power (axiomatic: Bröckling, Krasmann, and Lemke 2000; for protest: Baumgarten and Ullrich 2016). In this context, Foucault's (1979) panopticon, which long dominated the surveillance studies' notion of camera surveillance, continues to be inspiring. It raised the issue of social control through asymmetries of visibility (Boyne 2000) and thus paved the way for governmentality studies and their analyses of subjectifying processes. Yet, in some respects, pure panopticism restricts our gaze. The limitations of and uneasiness of employing Foucault's concept in complex social settings led to the invention of diverse substitute-opticons, such as superpanopticon (Poster 1990: 69ff), synopticon (Mathiesen 1997), or ban-opticon (Bigo 2006). ${ }^{3}$ What these critical adaptions address is the factual complexity and heterogeneity of visibility relations and, most importantly, the fluidity of their interconnections and repercussions (Bauman and Lyon 2013). The latter point is obviously in Marx's (2003) mind when he notes that surveillance, which triggers counter-surveillance (and may trigger counter-counter-surveillance), must be studied as a "conflict interaction process" of moves and countermoves. We use the notion of the "spiral of surveillance and counter-surveillance" (Wilson and Serisier 2010) to describe the unfolding dynamics of mutual adaptions of the parties in conflict. This spiral is one of the indirect effects of counter-surveillance, which is not at all intended by those who want to counterweigh state power. So, research has to systematically focus on the ambivalence of countersurveillance, especially but not limited to "copwatching" as suggested by Wilson (2012) or Schaefer and Steinmetz (2014).

Similar observations have been made in research on other behavioural techniques of protest policing (Fernandez and Huey 2009; Scholl 2010; Wood 2014); policing innovations are answered by innovations of protest repertoires and vice versa. The recent policing-style innovation strategic incapacitation, for example, is widely understood as a reaction to the protest repertoires of the global justice movements (Gillham and Noakes 2007). This "interactive diffusion" (della Porta and Tarrow 2012) of protest and police practices must also be studied in relation to the video recording of demonstrations.

Not only are visibility relations manifold in protests but also the number of involved parties and their specific desires and interests. Protest policing is not just an encounter of demonstrators and the police. It is a process that not only takes places under a media gaze that influences the actors who align themselves with the media and the media's logic (Cammaerts, Mattoni, \& McCurdy 2013) 4 but also under the scrutiny of government or parliamentary bodies and/or opposing protesters. ${ }^{5}$ Despite the obvious power imbalance, they are all competitors in attention and data economics (see Poster 1990: 75). Such reasoning resonates strongly with Haggerty and Ericson's (2000) concept of the surveillant assemblage, which conceptually tackles the convergence of once discrete surveillance systems that nowadays work together in a rhizomatic

\footnotetext{
${ }^{3}$ A long list of such concepts is provided by Ragnedda (2011; cf. Hempel and Töpfer 2009; Haggerty and Ericson 2000).

${ }^{4}$ Media play a role that cannot be overestimated as a central means of movements to achieve their aims (Rucht 2004; Schmidt-Beck 1990). The fact that the internet is becoming the preferred medium for circulating countersurveillance videos, makes us aware of the need to take seriously changes in the media landscape and the specific rules and patterns of 'new' media (especially their ubiquity and the sheer amount of information and speed) (see Schaefer and Steinmetz 2014). One of the most important developments for protest policing to be mentioned in this context is the increase in news production by police forces through social media channels (see Schug 2012) with which they partly bypass traditional media.

${ }^{5}$ In Germany, and most notably during our research, a considerable proportion of protest events were conflictual in this sense because of a wave of right-wing marches since 2014, which were usually accompanied by counterprotests. The political opponents often film each other to identify and deter opposing activists.
} 
structure. ${ }^{6}$ The functioning of this net "comprise[s] discrete flows of an essentially limitless range of other phenomena such as people, signs, chemicals, knowledge and institutions" (Haggerty and Ericson 608). Different, even opposing desires function together in deepening this data collection and processing net. The authors clear-sightedly contemplate that even actions 'for a good purpose' can contribute to the surveillant assemblage (Haggerty and Ericson: 618; see also Poster 1990).

Many revealing and consequential aspects become visible when using this fluid concept of the surveillance society as a heuristic framework. This perspective draws attention to the multiplicity of relevant actors, the interconnectedness of surveillance systems, the heterogeneity of motives, the difference between intentions and effects, the repercussions, and the ambiguities of counter-surveillance.

\section{Methods}

Our analysis rests on a diverse body of empirical data. The main source comprises twelve group discussions with activists about video surveillance and protest policing. The sample includes (left-)liberal, left, and right-wing protesters, as well as football fans. ${ }^{7}$ Through continuous comparative sampling we were able to cover a wide spectrum of political ideologies and protest strategies. The groups consisted of three to five participants who were recruited by contacting previously known activists and by directly emailing movement organisations. We chose the format of group discussions in order to allow for the reconstruction of meanings and norms of the respective groups. Furthermore, group discussions are expected to initiate self-supporting dynamics of narration, hence breaking up articulatory inhibitions, particularly when it comes to uncomfortable topics such as illegal behaviour. ${ }^{8}$

We also collected written material from the respective spectra, such as anti-repression manuals, leaflets, and publications through systematic research online and in archives specialised in social movements. Another source of information came from field observations of varying length carried out at more than 60 protest events. ${ }^{9}$

This main body of data is complemented by examples from relevant literature, eleven group discussions with police officers (predominantly riot police and video specialists), another eleven expert interviews

\footnotetext{
6 The "rhizome" as a model of decentralised, non-hierarchical structuring of culture and knowledge was introduced by Deleuze and Guattari (1987). It "ceaselessly establishes connections between semiotic chains, organisations of power, and circumstances relative to the arts, sciences, and social struggles" (Deleuze and Guattari: 7). Deleuze and Guattari provide several principles of the rhizome: heterogeneity, multiplicity, asignifying rupture, cartography, and decalcomania. The web of the rhizome has no identifiable beginning or end, which allows us to reconstruct the makeup of the surveillant assemblage at protest events from the very resistance against video surveillance.

${ }^{7}$ As a related case, football fans were included in the sample because they are confronted with the same police units in comparable settings (like fan marches). Technically, crowd policing and protest policing heavily overlap, although the legal framework is quite different.

${ }^{8}$ See Lamnek (1998) for details on the survey method. In the majority of cases, participants were given a video stimulus from a demonstration with visible cameras and were asked to freely discuss the scene and how it relates to their experiences at demonstrations. When the discussion stalled, interviewers asked for details on already mentioned aspects to stimulate further self-sustaining talk and ended the discussion (mostly after one to two hours) with reflective and wrap-up questions. Of course, this method has its limitations regarding group dynamics such as hierarchies, in-group pressure, conformity, etc. The reliance on communicable knowledge also limits access to implicit or habitualised practices.

9 The sample comprises all kinds of demonstrations with varying sizes, issues, political positions, (non)confrontational character, etc., which we observed from the sidelines or as participant observers from within. Fieldnotes were taken down during the events and systemised afterwards, sometimes accompanied by our own photographs, as well as official and media data on the demonstration. See Knopp \& Müller-Späth (2017) for details on methodology and results, especially the observation guidelines.
} 
with high-ranking police officers, and four with other experts, ${ }^{10}$ as well as a wide range of issue-related documents (like minor interpellations or police manuals). ${ }^{11}$ Most data were collected in 2015 and 2016. All verbal sources were transcribed and anonymised; for coding we used the software MAXQDA. The material was processed with open coding. For the overview of the different types of surveillance-related agency, we relied on qualitative content analysis with open and deductive coding phases (Mayring 2000). The typology was built inductively through constant comparison, refining existing typologies (e.g., Marx 2003) by adding the collective and relational dimensions they were lacking.

The concept of security cultures (see section 4.2; Knopp and Ullrich submitted) uses a comparative typology, which was developed in a steady interplay of empirical analysis and reflections sensitised by concepts from the literature (Strauss and Corbin 1998). ${ }^{12}$ While the notion itself derives from an in vivo code in the literature on consequences of surveillance on political organising (Starr et al. 2008), we widened the concept to fit the issue of reactions to video surveillance and our empirical data.

Although our data are primarily from Germany with some additional material from Austria, the results may partly also be applicable in other liberal (post-)democratic countries. ${ }^{13}$ Despite differences in police tactics and organisation, as well as differing protest cultures, global activism (e.g., related to world summits) leads to cooperation, diffusion, and appropriation of protest tactics in shared protest spaces (Teune 2012: ch. 2), as well as intensified collaboration between national police forces, especially at the EU level (Council of the European Union 2007; e.g., Aden 2015; Rikspolisstyrelsen 2013). These factors, as well as the common visual and media technologies, lead to convergence tendencies of protest cultures.

\section{Empirical Findings: Counter-Surveillance-Moves in Security Cultures}

In this section, we will present the different types of counter-surveillance-moves (4.1) and their contextual security cultures (4.2). Both diffuse across movements and protest generations through several forms of knowledge transfer (e.g., guidebooks, leaflets, workshops) and cross-sector observation. Thus, countermoves do not belong to a specific political current; seasoned moves are taken up by others who face similar situations. The fact that protesters can resort to these techniques on demonstrations appears to be one of the reasons why complete deterrence from participating in a protest (one of the most salient expectations in the discourse critical of surveillance) interestingly was not an issue in the self-testimonies. However, interviewees mentioned people who had stopped going to demonstrations or changed their scope of action. ${ }^{14}$ So what reactions did we find among the protesters who felt uncomfortable with video surveillance?

\subsection{Counter-Surveillance-Moves}

There is a great variety of techniques intended to subvert or contribute to the defence against video surveillance. The following six categories (consider cameras, disguise, attack, hide, sousveillance and formal ways of controlling the police, and cooperation) each cluster various discrete moves. Among them

\footnotetext{
10 Among them were (left-)liberal politicians who monitor protest policing on a regular basis, a professional demonstration photographer, a police union representative, and a police academy professor. Their statements are of minor importance for this paper.

11 See Ullrich $(2017,2018 \mathrm{a}, 2018 \mathrm{~b})$ for extensive descriptions of methodology of the police-related part of the study.

12 For further refining and to link it to the conditions of protest in the surveillance society, we relied on the theoretical concepts of "spaces of appearance" by Arendt and "spaces of surveillance" by Foucault (see Marquez 2012).

13 See also the references in footnote 2.

14 As we could only get in touch with activists in the literal meaning of the word, this might be a selection effect. Former protesters who shied away because of video surveillance are a group that is hard to recruit.
} 
are elaborated collective practices, which require prior preparation as well as more or less spontaneous reactions, which evolve from situational desires, often feelings of indignation, fear, etc. about ongoing police actions. Fundamental differences between the clusters, which we use for conceptual ordering (see Figure 1), lie in the degree of cooperation with the police (axis conflictive vs. cooperative) and in their directionality: if moves focus on the demonstration itself, e.g., they are 'work on the (collective) self,' or on the police and their cameras, or on third parties (axis inwards vs. outward).

\section{Consider Cameras: Awareness, Reflection, and Knowledge}

This first category serves as an umbrella, covering the preconditions of the following (re-)actions on video surveillance. It mostly concerns how and whether cameras are taken into account at all.

Amongst our group discussions, awareness for cameras is disparate. Some stated that they notice cameras only occasionally and when used in their proximity. Yet, others are routinely on the lookout for police cameras when they enter assembly spaces and advise companions about their location. With this information, they map the area with respect to surveillance and special police units. Resorting to this knowledge, they interpret police tactics, the police's (alleged) focus on certain protesters, and they define their own respective role. The reflections on video surveillance are characterised by uncertainty about the reasons for deploying cameras, the situational meaning, and the actual focus of the cameras. This lack of certainty is processed by interpretative patterns about the police and the state in general, which influences respondents' trust in the police's use of video data (Knopp and Ullrich submitted).

To better prepare for such situations, the acquisition of knowledge concerning cameras is becoming ever more important. Yet, there was also a lot of divergence concerning knowledge about the legal framework surrounding the topic in our focus groups. Some protesters were surprised that special laws about video surveillance at assemblies even existed, while others based their arguments on profound knowledge of assembly legislation and court decisions. Especially for collective and organized forms of resisting video surveillance, anticipative knowledge, and experience with policing of certain protest events is required as protesters may have to adapt to reactions and actions by police on the spot.

\section{Disguise}

"Disguise" summarises defensive techniques aimed at rendering the activists non-identifiable before, during, or after conflict situations.

As video surveillance permits the identification of small details, especially militant demonstrators try to reduce personal traces to a minimum, e.g., by wearing similar and non-descript clothing from head to toe. Being predominantly anticipatory in character, these techniques require a certain degree of preparation, for example, having black clothes or balaclavas available.

Disguise also involves the situational changing of clothes, the use of banners or umbrellas as shields and the avoidance of surveilled spaces at demonstrations to fulfil (militant) protest goals. In our group discussions with leftist activists, masking, which is illegal at assemblies, was the most frequently stated and controversially discussed technique (cf. section 4.3.2). The most infamous protest method, which includes several of these techniques, is the so-called black bloc. Clearly, these practices are (and have to be) applied collectively to be effective. Protest actors thereby often leave the framework of institutionalised conflict management to opt for confrontative repertoires (e.g., refrain from officially announcing assemblies) - for which police could prepare and control assembly spaces - to be able to perform and facilitate civil disobedience or militancy.

\section{Hide}

With "hide," we refer to defensive and predominately legal practices with which protesters spontaneously and individually reduce their visibility when confronted with cameras. 
Activists report these acts as routine behaviour that is usually applied independent of planned protest actions. These moves are defensive acts within the demonstration, such as spontaneously turning away, covering the face with the hand, or putting on caps or hoods. Some report that they hide behind taller persons, in masses, or just stay away from cameras. Leftist discussion groups and football fans reported that for them, hiding also replaced more ambitious tactics, such as disguise-moves, because the latter may provoke police sanctions. Besides these situational and mostly unplanned moves, it is common in radical movements to ignore summons to police interviews because (among other reasons) they may be accompanied by photo identification procedures. The hiding of forbidden Nazi-symbols (e.g., tattoos, clothes) within the neo-Nazi scene can be observed due to Germany's restrictive legislature on this issue. In general, although hiding is non-cooperative, it is usually not intended to fuel confrontational dynamics, although it is triggered by negative emotions.

Attack

"Attack" is offensive or aggressive physical or verbal behaviour against agents or devices of surveillance and their operability.

A very common form are verbal attacks taking place every now and then in standard chants, some of which explicitly focus on videotaping such as "Cameraman-asshole!" Targeted physical attacks on cameras or camera operators during demonstrations are not reported as a standard move, neither by activists nor the police. But militant actions aimed at destroying or stealing cameras may occur spontaneously - such as the camera robbery by a youngster described by one of our interviewees-and they are characterised as David-versus-Goliath scenarios, in which the powerless demonstrators surprisingly win.

Militant guidebooks suggest more organised ways to make cameras inoperable. They suggest sabotaging cameras (although mainly CCTV) with spray cans, cable cutters, hammers, or bags. On one side, it should safeguard anonymity during militant action by manipulating the conditions under which they are performed. On the other side, attacking cameras can be framed as symbolic political action against the 'surveillance state.' Hence, the offensive counter-move categories of "disguise" and "attack" may comprise both political and tactical reasoning.

Sousveillance and Formal Ways of Controlling the Police

"Sousveillance" is surveillance 'from below' intended to document events, including police conduct, from the protesters' perspective with the possible use of the data to scandalise police misbehaviour or file charges. Sousveillance is practiced individually and spontaneously as well as in organised and collective ways, also known as "copwatch" (Schaefer and Steinmetz 2014; Wilson 2012). Besides the ubiquitous "citizen journalist" who uses a smartphone, several professionals (parliamentarians, journalists associated with movements) and specialised movement organizations (e.g., the "Critical Lawyers" and several local and national groups of demonstration observers and so called "legal teams") scrutinise police actions at protest events. The documentation of officers' (mis)behaviour facilitates other measures of controlling the police: lawsuits and disciplinary complaints, media attention, and political campaigns to influence the legal framework of protest events.

As a simple form of sousveillance, demonstrators directly complained about the use of video cameras to the camera operator, but with little success, as interviewees on both sides stated. However, a journalist specialised in demonstrations uttered the impression that his presence affected the behaviour of the police: officers turned down illegally used cameras and stopped mistreating demonstrators when they realized they were being watched. 
Concerning media coverage, we can observe that footage of police misconduct may provoke public scandals, put it on the political agenda, and lead to legal regulations - not always - in the interests of protesters. ${ }^{15}$ There are cases in which coverage of illegitimate police behaviour altered public discourse and led to a more protester-friendly media coverage (see Greer and McLaughlin 2010; Knopp and Ullrich 2016; Neumayer and Stald 2014; Ullrich 2014). Protesters' pictures also serve as evidence in legal procedures against police or approval of the protester's innocence (ibid.).

However, activist sousveillance goes far beyond watching and filming the police with given devices. 'Hacktivism' led to technological innovations to produce systematic "counter-evidence" (Tuma 2017; Ullrich 2014). Chaos Computer Club (CCC) activists, for example, synchronised several smartphone videos of a police attack during a demonstration against state surveillance to reconstruct the incident from multiple perspectives. Even drones have been built and are used by protesters. A range of smartphone apps facilitate easy, automated, and disguised direct upload of footage to the internet platforms of civil rights organisations.

Such direct sousveillance is supported by formal actors who monitor police, e.g., by movement-friendly parliamentarians, who raise minor interpellations about surveillance technology or incidents at protests. Last but not least, political activists and football ultra-fans also launched campaigns against state surveillance, such as "Freedom instead of fear" (2001 ff.) or the campaign for compulsory identification labels for police officers (Daphi, Lê, and Ullrich 2013). Such political campaigns are often accompanied by critical art interventions. ${ }^{16}$ An integral part of the general campaigning in this field is legal complaints of unconstitutionality against new laws introducing surveillance measures.

\section{Cooperation}

"Cooperation" is the communicative organisational coordination of protest with the police. It serves different purposes, one of which is to minimise surveillance through preventative appeasement of the police. The degree of cooperation is a key factor in the police's categorization of protesters, the selection of policing styles, and thus also in the deployment of video cameras (della Porta and Reiter 1998; Ullrich 2017; Wahlström 2011). In our research we found different degrees of cooperation, from behaviour that is uncooperative or limits cooperation, to the absolute legal minimum of formally announcing the demonstration on one hand, to extensive collaboration on the other.

An extreme form of cooperation is what we call "peer monitoring" (Andrejevic 2005). This includes constant self-optimisation and pre-emptive obedience to police orders and is established by means of intense communication with police. While such collaboration also serves the purpose of protecting demonstrators against opponents with the help of the police, others cooperate mainly to keep police interference and surveillance at a low level. Nevertheless, interviewed antifascist activists, for example, reported harsh policing (extensive access controls, police kettling tactics, and so forth) despite good prior dialogue. They experienced cooperation as a Sisyphean task: necessary and carried out while regularly causing frustration. We also found exceptional occasions of cooperation, e.g., a meeting of football fans with police officers to raise mutual understanding. Right-wing activists reported collaboration with the police in the prosecution of their political enemies by handing over video footage of antifascists to the police.

\footnotetext{
15 In Austria several sousveillance videos of police violence provoked scandals resulting in an increase of video surveillance at demonstrations and the implementation of body-cams for patrol officers to secure full coverage of their actions (Knopp and Ullrich 2016).

${ }^{16} \mathrm{We}$ will not detail this wide field here, as it only very indirectly affects demonstrations. For details, see Brighenti (2009) and Galdon Clavell (2014).
} 
Cooperation techniques can thus be collectively organized, institutionalised, or performed individually. Cooperation first and foremost influences the behaviour of protesters inside a demonstration andalthough its outcomes are uncertain — aims at altering the nature of policing.

\subsection{Security Cultures in Protest Movements}

The choice of carrying out a counter-surveillance move in a specific protest setting and whether the move is a part of the repertoire of certain groups are not random. For example, we have seen that choices depend on the general relation of the respective protest groups to the police and their mutual willingness and ability to cooperate. To better understand the bases on which these choices are made, we propose the use of the concept of movement-specific security cultures. We borrow the term from Starr et al. (2008), who use it to describe organisational practices of left-wing groups "in order to protect the organization and members from persecution" by state authorities (10). In fact, the problem of securing demonstrations and protesters seems to be a more variegated issue. (Left-)liberal groups, for example, generally evaluated police and video surveillance - if it is not too extensively directed at themselves - not as a threat but as a protection of their demonstrations (and therefore seldom engaged in counter-surveillance). Thus, it is necessary to widen Starr et al.'s definition to cover a range of protest groups and their relations to surveillance and the police. We therefore use the term security culture to designate established movement or group specific norms and sets of practices intended to secure political agency under conditions of perceived threats.

The development of security cultures has to be understood as a reaction to the exposure to confrontation, police tactics, and videotaping, etc., which transform assemblies into "spaces of surveillance" (Marquez 2012). Relying on Hannah Arendt's term of "spaces of appearance," 17 in which identities are shaped through appearance of a fundamental equality and direct mutual visibility of individuals, Marquez argues that public spaces always shape identities in double-sided relations of hierarchical and horizontal visibility and power. This simultaneity of dissimilar visibility relations is a constitutive quality of protest and a dynamic element in the (trans-)formation of security cultures. Protestors are forced to process resultant contradictory desires for anonymity (to repel surveillance by police or opponents) and visibility (in relation to other protesters and the public), which forms an important part of their political agency (Freudenschuß 2015). ${ }^{18}$ The ambiguities of visibility cause debates and reflections about the questions of how to make protest visible and in relation to whom. In Germany, we therefore find that almost every political current is equipped with 'rules of conduct.' 19

Spoken in Foucauldian terms, security cultures are productive effects resulting from power relations between protesters, their opponents, the police, and audiences. Security cultures form integral parts of protest cultures and process the specific vulnerabilities and visibilities of protest groups, thus shaping activists' identities (Freudenschuß 2015). However, security cultures not only emerge and transform in confrontation with surveillance and policing but also with general norms and practices in protest cultures. They are embedded in the political thought of the respective political current and in their strategic goals. Figure 1 shows the counter-moves practiced within the four security cultures we identified.

\footnotetext{
${ }^{17}$ It is almost a truism that social movements and protest rely heavily on publicity and visibility to call attention to marginal groups and claims or unmet social problems (Hellmann 1996; Luhmann 1996).

18 This should clearly show that, in the case of video surveillance at demonstrations, the ingrained juxtapositions of surveillance and privacy cannot encompass the ambiguities in the modes of action in which demonstrators are forced to act.

19 The main behavioural techniques often derive from radical left solidarity organizations and have diffused throughout other political spectra. One of the main sources is the guidebook What to Do When the Going Gets Rough? published by "Rote Hilfe."
} 


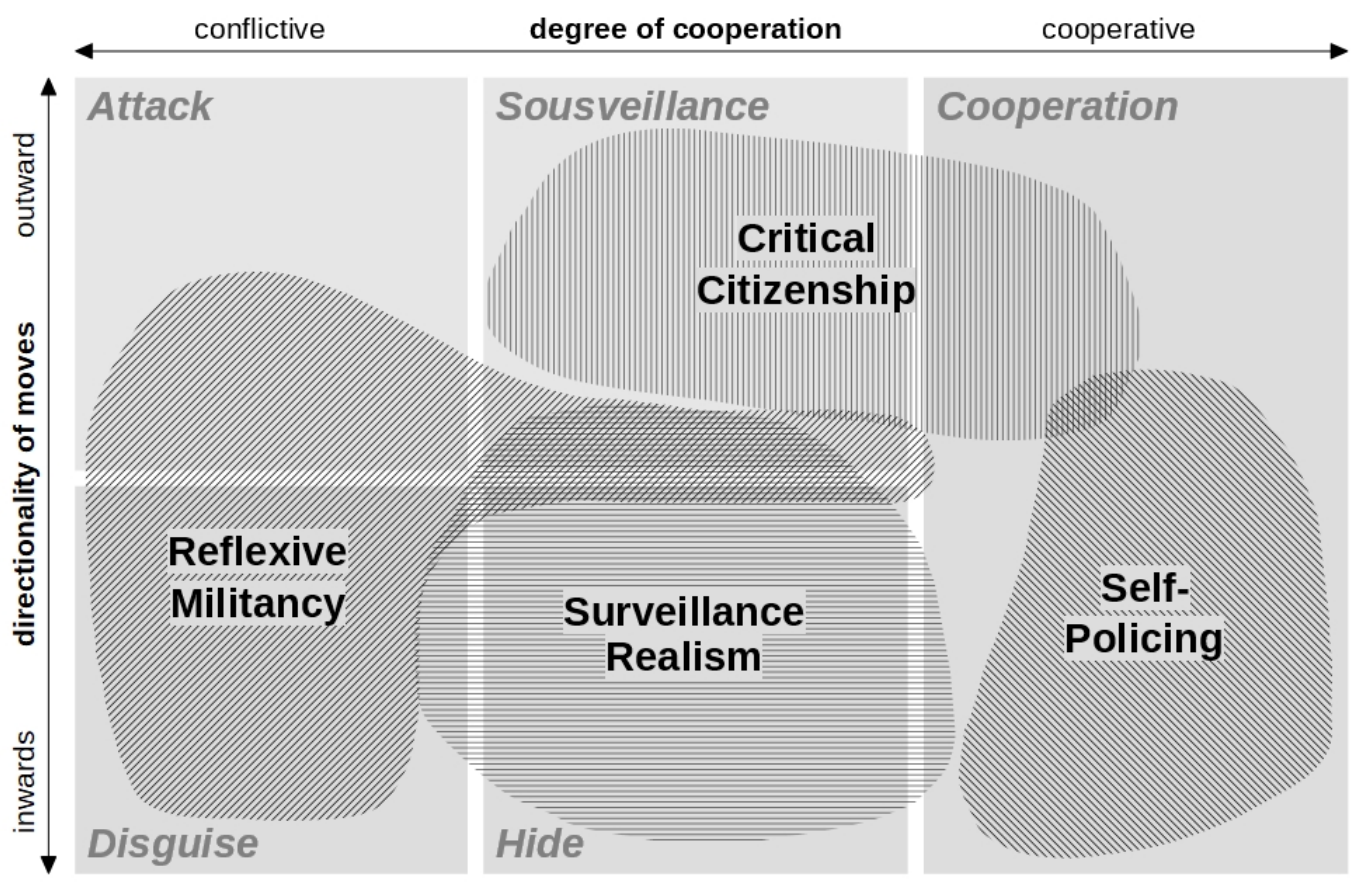

Figure 1. Counter-Surveillance-Moves (grey squares) and Security Cultures (hatched irregular shapes; a security culture's 'signature move' is indicated by the location of its name in the square of the corresponding move).

\section{Reflexive Militancy-Convergence of Anonymity and Agency}

In this security culture, police are perceived as an overly powerful and non-trustworthy opponent against whom safety and agency must be maintained. Although reflexive militancy is mainly discussed by autonomous and radical left demonstrators, we can also find its traces in other groups (which may derive from diffusions of tactics and knowledge as well as from exposure to video surveillance and police repression). There are several guidebooks explaining how to sabotage CCTV-cameras and how to behave in conflicts with the police or during arrest. Reflexive militancy questions habitual 'paranoia' among militant protesters. It suggests a convergence of militant agency and counter-surveillance through techniques such as masking, sabotage, or wearing similar black clothes. Thus, black bloc tactics and other non-cooperative counter-moves are typical for this security culture. Their aim is to enable militant and disobedient agency through a high degree of collective anonymity. The collective practice itself contributes to the desired "non-identifiability" (Marx 1999). To reach this aim there is a need to adapt to new surveillance and policing techniques and to develop counter-techniques, which empower the protesters' militancy. As an interviewee from an autonomist group summarised: "We shouldn't be paranoid, thinking 'oh no I can't do anything anymore,' but ... stay clear-headed and notice when things turn heated and if we have to somehow change the course of action [our translation]." Consequently, protesters in this security culture are very sceptical towards demonstrators who film during demonstration because every published picture is dreaded to potentially contribute to persecution. Sousveillance is mainly seen as ineffective considering the perceived power of the police. Anonymity for them is a value in itself and counter-surveillance can be understood as a matter of resistance. Related moves, prevalent among anarchists or autonomist groups, are also appropriated by militant neo-Nazis. ${ }^{20}$

20 This appropriation is characterised by a wider discussion about right-wing agency when it comes to leftist blockades of their demonstrations. The "nationalist black bloc" is thus a copy of as well as a tactical adaption to the successful strategies of political opponents. 


\section{Surveillance Realism-Resisting and Meeting the Gaze}

The groups representing this security culture experienced similarly harsh or violent policing styles, which create distance from the police. In contrast to the militants, they still harbour some basic confidence in law compliance by the police. They highly desire anonymity; disguise-moves are accepted and occasionally used. However, these techniques are criticised because of two negative consequences they come with: “... when people mask, it makes a much more extreme impression .... Teenagers may come to demonstrations because they are interested and then wonder 'What's going on? Why do they dress like that?' because they don't understand what's going on and may think it is dangerous [our translation]." Masking and uniform clothes are seen as a negative visual demarcation, which may discourage less experienced demonstrators and repel the public. Popular support and mobilisation success are accordingly valued higher than anonymity. Apart from discouraging (potential) demonstrators, activists also blame illegal disguise-moves for entailing repressive police measures. The tense relationship between anonymity and political agency is resolved by avoiding certain counter-moves and substituting them with hiding-moves or more or less fatalist disregard of surveillance.

\section{Critical Citizenship}

"Critical citizenship" applies a civil-society concept of citizen-state-relations, as is constitutive for "movement societies" (Rucht and Neidhardt 2002), to the subfield of the relations between police and protesters. In principle, there is a positive attitude to the order of law, to the state, and to the police, but as an interviewed queer activist stated: "I think, we need critical citizens ... and it is quite good too that we have no paternalistic understanding of the state. The state isn't our sugar daddy [our translation]." This active role of the citizen is also claimed in interaction with the police. Therefore, these activists are prepared to criticise police misbehaviour, violence, or vast surveillance. In line with other more exposed groups, they see the need to control the police. However, the police's filming of 'disturbers' is accepted. Significant counter-moves are sousveillance and formal ways of controlling the police, which are legal and supposed to be effective in order to limit state power. Achieving anonymity is not an urgent desire during a demonstration. Rather, low surveillance and preservation of privacy are more general political claims.

\section{Self-Policing}

"Self-Policing" fulfils police's normative requests towards peaceful protesters. It is deeply connected to police- and state-friendly attitudes. The (left-)liberal interviewees belonging to this security culture perceived police mainly as a protector and supporter of their demonstrations; surveillance is therefore mostly seen as a protection too. In contrast to the other types, these protesters had very few or no experiences with over-policing or extensive surveillance. The demonstrators themselves engaged in preventing possible breaches of law by containing militant demonstrators, obeying the police, and enforcing their orders. Political agency was thus maintained through a cooperative relationship with police. A major form of 'counter-surveillance' (e.g., mainly surveillance prevention) in this security culture is strict cooperation and peer monitoring resulting from the perception of a plethora of imminent threats for their demonstrations and an ideological refusal of political violence. An NGO-activist describes how complex these systems of self-policing can be: "[We want] everything to work out fine...We have two or three steward positions apart from the separate car or walking group, we ourselves form the supervising team, which monitors the surroundings. The other stewards can work autonomously and are connected to us through the driver. This is a form of networking that also provides higher chances for the police to carry out their real tasks - maybe even better — without using 500 cameras [our translation]."

A special type of self-policing, which may be termed 'political self-policing,' can be found in the neoNazi scene. It is not necessarily motivated by respect for the law, even though the legislature on Nazi symbols and hate speech definitely influences this behaviour, but by striving for a better image of the groups in public opinion and seeing discipline as a group-specific behavioural ideal. In contrast to 
'surveillance realism,' this is an authoritarian way to handle demonstrations. Participants are prompted to follow strict orders given by mobilizing organizations, such as rank-and-file marching, smoking bans, or obligations to shout only 'politically adequate' slogans.

With their respective practices and codes of conduct, security cultures also try to minimise surveillance. Their means and signature moves differ, yet whatever they do, the results do not lie in the protesters' hands only. This is what the next subsection is about.

\subsection{Ambiguities of Appearance and Surveillance}

The codes of conduct for protesters mentioned above as well as myriads of videos scandalising inappropriate police behaviour in social media speak volumes about the hopes protesters pin on techniques aimed at balancing police powers. However, counter-surveillance contributes to developments that do not serve the desired purpose and may even deepen the surveillant assemblage at protest events (overview in table 1). We will elaborate on these aspects by analysing more closely two moves with the most disparate intentions: sousveillance (widening the field of visibility) and disguise (maximising non-identifiability).

\subsubsection{Sousveillance and Backfire-Arms Race and Media Battle}

The video of police officers beating African American Rodney King 81 times shocked the world in 1991, and since then scholars and activists have had high hopes that sousveillance would increase the accountability of police and show a different perspective to the world. Even sousveillance-sceptical protesters acknowledge the occasional achievements of protesters' own image production. But which aspects may weaken or outweigh the intended outcomes or even lead to "backfire" (Goldsmith 2010: 929)?

Although there are instances of sousveillance footage helping to turn tides in the discourse about a specific protest (see, for example, section 4.1; Greer and McLaughlin 2010; Knopp and Ullrich 2016; Neumayer and Stald 2014), most videos obviously do not surpass the media attention threshold. Measured against the sheer amount of available footage (see Schaefer and Steinmetz 2014: 513), only exceptional cases under conducive conditions are able to challenge the police in their privileged role as the "primary definer" (Greer and McLaughlin 2010: 1043) who sits on top of the "hierarchy of credibility" (Becker 1967) in mainstream media and criminal proceedings (cf. Singelnstein 2014).

Moreover, research findings suggest that public reactions to sousveillance footage are complex and dispersed. An analysis of viewer comments on YouTube videos of police violence showed a polarisation of the audience. On specific occasions, the majority of commentators have supported the police position, with many using smear language and openly calling for more violence by the police (Schug 2012). Concerning general attitudes, a Finnish survey suggested that scandals about police misbehaviour can lead to solidarization effects and eventually lead to increased trust in the police (Kääriäinen, Isotalus, and Thomassen 2016). In our group discussions, we found comparable reactions. Especially activists engaging in self-policing criticised that sousveillance presents a wrong image of the police to the public as it implies that police would only use escalatory violence. Some speculated that there were "professional groups" consciously enacting such scenes to exploit images of police violence for their political aims. Having seemingly scandalous footage available does neither automatically entail a scandal, nor does a scandal necessarily lead to improvements in the ways in which the creators of the scandal had hoped.

Furthermore, police of course use all available images, including those from publicly available private sources, for their own investigations. Therefore, material intended to convict police may eventually play a part in convicting demonstrators (see Wilson 2012).

The reactions of police to sousveillance, which they most consciously register and largely consider illegitimate or unnecessary (Ullrich 2018a), represent another important unintended effect. 
Police (counter-)counter-moves can be directed against journalists, for example. Our police interviewees often had unfavourable opinions about journalists. And they had even more unfavourable views when it came to other observers of demonstrations. We collected many reports about police obstructing protests and protests policing coverage. These reports ranged from lack of protection (of journalists against violent neo-Nazi protesters), to equipment seizure and (illegal) attempts to delete footage. Such behaviour is not new and was already widely reported in the pre-digital times of video-activism, as well as in other countries as an "ambiguit[y] of counter-surveillance" (Wilson and Serisier 2010).

As both sides act and react, their relative strength becomes a matter of importance. The structural disadvantages are obvious and have their share in the de-facto non-existent prosecution of police violence in Germany (Singelnstein 2014). First of all, the police have strong "definitional power" (Feest and Blankenburg 1972; Ullrich 2018b) and the legal as well as material means for its immediate exertion. The most striking power difference (besides the precondition of the police monopoly on the use of force) with respect to video recordings lies in the disguise capabilities of police. The police wear uniforms, which are often comprised of helmets and, more and more frequently, balaclavas without individual identification tags, while masking and wearing uniforms is illegal for protesters in Germany. 'Behind' the camera, police are also equipped with better (material) opportunities to gather, store, analyse, connect, and use information, especially with their privileged access to prosecutors. Figuratively speaking, the protesters' mobile phones encounter police helicopters and specialised, highly technological surveillance vehicles.

Protesters are thus primarily forced to rely on the unpredictable effects of their images in the public sphere. However, even in this field police reaction is gaining traction. Although the German police forces are not generally up to par with the media efforts of professional movement campaigners, they have visibly increased their public relation and social media presence. Several local or regional units have formed social media teams, which disseminate information through their various internet platforms, including coverage of demonstrations. In doing so, the police are pursuing the same goals as social movements - in other words, spreading their unfiltered point of view to the public (Berthel 2016; Schug and Kersten 2013). The controversial case of the "Blockupy" demonstrations against the opening of the European Central Bank in Frankfurt in 2015 demonstrated that in this way police can easily cross the line between ensuring transparency about their work on one hand and, on the other, active political influence on demonstrations and their public image to an unconstitutional degree (Bartlau 2015). The police social media team in Frankfurt became notorious and seminal with their mixture of substantial information and ironic comments, outrage-seeking messages in capital letters, and spectacular, tabloid-style images accompanied by tendentious remarks critical of the protest. ${ }^{21}$ Demonstrators were even given suggestions on how to behave well. Yet, this seemed to be more than just an aggressive public relations tactic. Civil rights organisations that monitor demonstrations on a regular basis suspected that police did not intervene in certain situations (i.e., did not stop violence or extinguish burning barricades) to produce scarring images (Steven 2015). Some of the pictures were then used in the context of different peaceful marches, contributing to the creation of a different image of these events. Recalling our opening lines, it becomes clear that this encounter of police and protesters and their mutual efforts in steering image production is anything but balanced.

Only occasionally do the protesters realise this close interrelatedness of the new visibility of both sides. Existing criticism is deeply linked to security cultures aiming at different degrees of anonymity and safety. Negative aspects related to the production of images by protesters have been brought forth especially by activists of the radical left. One of the counter arguments is that sousveillance may contribute to the

21 One example was an image of a crowd of protesters predominantly dressed in black with the comment "Colourful protest?" "Colourful protest" in Germany being a synonym for peaceful, moderate, and legitimate demonstrations. 
persecution of disobedient demonstrators, provoke police violence, the seizure of cameras, and other repressive measures. Produced images may also be utilised by political opponents and thus increase vulnerability of their own group and prove ineffective in the end, when considering the power differences.

These interpretations of the consequences of sousveillance result in the strategic adaption to the enormous importance of images and the ubiquity of cameras of all kinds. In the security culture "reflexive militancy," we can observe a certain professionalisation of the use of video footage. Solidarity organisations and media producers close to the movements such as Indymedia prompt photographers to anonymise/pixelate their photos; other demonstrators are expected not to take pictures and leave it to legally protected activist journalists to do so. In the security culture of "Surveillance Realism," activists may collect photos and videos systematically for court trials and hold them back from social media to gain advantages against state prosecutors. In the struggle for images these protesters may just as well decide to be identifiable in order to produce better images to their liking - which can compete in the economies of attention.

\subsection{2 (Black) Blocking Surveillance, Self-Stigmatisation, and Irony}

Sections of militant protesters, who are not confident in their abilities to counter surveillance by producing their own images, focus even more on achieving anonymity, e.g., using disguise techniques, for which the black bloc is emblematic. Despite being quite a different approach than sousveillance, it is enmeshed in comparable dialectics.

As mentioned above (section 2.1), contemporary protest policing styles rely heavily on their selectivity. German police forces therefore developed classification systems for protesters, often based on a traffic lights system: red for 'disturbers,' yellow for 'potentially violent protesters' and those who show solidarity with 'transgressive' protesters, green for the 'peaceful.' Clearly visible features related to disguise-moves, such as black clothing, utilities for masking, and so forth, explicitly serve as indicators for the red and yellow category; outer appearances are thus taken as emblems of threat categories (Ullrich 2017). For those categorised as 'red' this may have serious consequences for the way in which they are policed, including more surveillance, "strategic incapacitation" tactics, databank records, and arrests (Dießelmann 2015; Ullmann 2008). Consequentially, counter-moves aimed at increasing anonymity may foster police awareness and thus protester visibility, because what is invisible is perceived as suspicious and receives special attention.

However, disguise-moves do not only affect police classifications and practices. 'The masked disturber' is a collective symbol for (a-)political violence also in public discourse (Dießelmann 2015). In mainstream interpretations, the appearance of a black bloc reduces the legitimacy of protests and this again makes the justification of harsh policing more likely. This is why some left-wing interviewees were concerned about the way in which their demonstrations (dominated by activists wearing black) are perceived by the general public and by inexperienced (potential) adherents. There are remarkable reactions to these ambivalences. Besides situational changes in clothing, which we mentioned above as a disguise-technique, activists repeatedly satirised public myths about black blocs. At recent protest events, other uniform colours were used to achieve anonymity for civil disobedient actions while trying to avoid discursive stigmatisation. The spiral of moves and counter-moves continues. 
Table 1. Summary of Ambiguities of Counter-Surveillance-Moves and Backfire

\begin{tabular}{|l|}
\hline The ambiguities of counter-surveillance \\
\hline High media attention threshold, police role as "primary definer" \\
\hline Indifferent or contrary reactions by audiences and other protesters \\
\hline Police counter-counter-moves \\
\hline Police social media activity \\
\hline Use of sousveillance images for prosecution \\
\hline Inequality of (legal, material, and legitimacy) resources \\
\hline Self-stigmatisation through infamous moves \\
\hline $2^{\text {nd }}$ level of social sorting \\
\hline
\end{tabular}

\section{Conclusion: Antagonistic Dancers and the Spiral of Surveillance and Counter- Surveillance}

The video surveillance of protests does not leave the affected untouched. Among the reactions there are many intended to subvert surveillance by avoiding, surpassing, or actively challenging it. There are also practices that obediently fulfil police expectations towards demonstrators. Also, (at least gradual) deterrence from demonstrations is mentioned as a protester reaction. However, the focal point of the activist agency is not deterrence but a more-or-less conscious adaptation to a situation, which is characterised, among other facets, by video surveillance. If and how certain counter-surveillance moves are applied depends on political interpretations, the degree of exposure, perceptions of conflict dynamics, and how different protest spectra process all these in their respective security cultures, cultures in which political and tactical aspects are inseparably mixed.

However, in the surveillant assemblage that "transcends institutional boundaries," no move has simple effects because "systems intended to serve one purpose, find other uses" (Haggerty and Ericson 2000: 616), not to mention feedback and interactional effects, which are illustrated by the critical analysis of sousveillance. Once a video enters the rhizomatic network of data-whether it was shot with the intention of strengthening police accountability, as a keepsake of an extraordinary experience, or to satisfy social media followers - the photographer as well as the photographed lose control of the image. It can be used to satisfy a diversity of desires of a range of consumers and reproducers (among them police and political opponents); 22 it may also initiate even more desires, reaching its peak with the paradoxical self-interest of protesters to be under more surveillance if it potentially proves their innocence (Knopp and Ullrich 2016: 531). The use and effects of images thus quickly decouple from their primary intentions. The antagonistic dancers - the police and protesters - engage in a closely intermingled performance with uncontrollable effects that eventually culminate in their growing visibility "such that no major population groups stand irrefutably above or outside of the surveillant assemblage" (Haggerty and Ericson 2000: 618).

Our introductory story and several sousveillance concepts may suggest the establishment of an equality of arms between protesters and police. However, as we have shown, surveillance is still defined by uneven power relations and selectivity (Bauman and Lyon 2013; Hier 2003). Indeed, hierarchical power relations function as a condition of the dynamics fuelling the spiral of surveillance and counter-surveillance. To a certain degree, motivations for sousveillance derive from the inherent perspectivity and selectivity of surveillance. The police perspective encounters the activists' perspective, which is also highly selective.

22 This is why some interviewees said they would not only hide or mask because of police surveillance but also because of protesters filming with their mobile phones. 
The advancements of one side drive the other side to go ahead with their own technical, legal, or tactical adaptions.

Following David Lyon (2001), the social sorting and ordering of societies into populations is a basic function of surveillance. We have shown that within selective styles of protest policing the very reactions to video surveillance become characteristic for a second level of social sorting, which derives its suspicion and threat categories of 'dangerous classes' and 'risky individuals' also from certain counter-surveillance practices. ${ }^{23}$ While the police sorts and defines protesters even according to partly political 'risk categories' (Ullrich 2017) and spreads classifications of 'good' and 'bad' protesters throughout society, it has impacts on the protest movement's political opportunities. Certainly, under these circumstances of widespread surveillance, police become an important "subject of social change" (Hirsch 1986: 118 [our translation]), because they do not just influence the appearance of protest identities and changes in protest cultures but the conditions for social change as such.

The analysed field of video surveillance of demonstrations is a brilliant example, not only for highlighting the deep rhizomatic character of the surveillant assemblage but also for showing how the rhizome grows in a field of conflict and how desires come into being in an interplay between structure (surveillant assemblage) and agency ([counter-]surveillance). The strategic and unintended expansion of the surveillant assemblage (cf. Schaefer and Steinmetz 2014) is thus driven by (small) struggles for visibility and anonymity, which constitute a spiral of surveillance and counter-surveillance. It is the context of the surveillant assemblage, which contributes to the ambiguities in which the antagonistic dancers' surveillance and counter-surveillance are still part of the same dance.

\section{References}

Aden, Hartmut, ed. 2015. Police Cooperation in the European Union under the Treaty of Lisbon: Opportunities and Limitations. Baden-Baden: Nomos.

Allan, Stuart, and Einar Thorsen, eds. 2009. Citizen Journalism. Global Perspectives. New York: Peter Lang.

Andén-Papadopoulos, Kari. 2014. Citizen Camera-Witnessing: Embodied Political Dissent in the Age of "Mediated Mass SelfCommunication." New Media \& Society 16 (5): 753-69.

Andrejevic, Mark. 2005. The Work of Watching One Another: Lateral Surveillance, Risk, and Governance. Surveillance \& Society 2 (4): 479-97.

Backes, Otto, Rainer Dollase, and Wilhelm Heitmeyer. 1998. Wie groß ist die Fremdenfeindlichkeit in der Polizei? Eine Analyse zu Risikokonstellationen im Polizeialltag, ed Institut für interdisziplinäre Konflikt-und Gewaltforschung. $I K G$ Newsletter 9 (1): 4-11.

Bartlau, Christian. 2015. Offen, transparent, verfassungswidrig. Die Zeit, July 6. http://www.zeit.de/politik/deutschland/2015-07/polizei-twitter-verstoss-gegen-recht/komplettansicht.

Bauman, Zygmunt, and David Lyon. 2013. Liquid Surveillance: A Conversation. Hoboken: Wiley.

Baumgarten, Britta, and Peter Ullrich. 2016. Discourse, Power, and Governmentality: Social Movement Research with and beyond Foucault. In Social Theory and Social Movements: Mutual Inspirations, eds Jochen Roose and Hella Dietz, 1338. Wiesbaden: Springer Fachmedien.

Becker, Howard S. 1967. Whose Side Are We On? Social Problems 14 (3): 239-47.

Berthel, Ralph, ed. 2016. Polizei im digitalen Zeitalter. Teil III. Rothenburg/Oberlausitz: Hochschule der Sächsischen Polizei (FH).

Bigo, Didier. 2006. Globalized (In)Security: The Field and the Ban-Opticon. In Translation, Biopolitics, Colonial Difference, eds Naoki Sakai and Jon Solomon, 109-55. Hong Kong: Hong Kong University Press.

Boyne, Roy. 2000. Post-Panopticism. Economy and Society 29 (2): 285-307.

Brighenti, Andrea Mubi. 2009. Artveillance: At the Crossroads of Art and Surveillance. Surveillance \& Society 7 (2): $175-86$.

Bröckling, Ulrich, Susanne Krasmann, and Thomas Lemke, eds. 2000. Gouvernementalität Der Gegenwart. Studien Zur Ökonomisierung Des Sozialen. Frankfurt/Main: Suhrkamp.

Brusten, Manfred. 1971. Determinanten selektiver Sanktionierung durch die Polizei. In Die Polizei. Soziologische Studien und Forschungsberichte, eds Johannes Feest and Rüdiger Lautmann, 31-70. Opladen: Westdeutscher Verlag.

Cammaerts, Bart, Alice Mattoni, and Patrick McCurdy, eds. 2013. Mediation and Protest Movements. Bristol, UK: Intellect.

${ }^{23}$ The ongoing efforts of governments to decrypt and even forbid encrypted communication suggest that the same second level of social sorting may take place in other fields of surveillance too. 
Council of the European Union. 2007. Council Recommendation Concerning a Handbook for Police and Security Authorities Concerning Cooperation at Major Events with an International Dimension. Brüssel. [Accessed July 20, 2017]. http://www.statewatch.org/news/2009/dec/eu-troublemakers-handbook-2007.pdf.

Daphi, Priska, Anja Lê, and Peter Ullrich. 2013. Images of Surveillance: The Contested and Embedded Visual Language of AntiSurveillance Protests. In Advances in the Visual Analysis of Social Movements, eds Nicole Doerr, Alice Mattoni, and Simon Teune, 35:55-80. Bingley, UK: Emerald.

Death, Carl. 2010. Counter-Conducts: A Foucauldian Analytics of Protest. Social Movement Studies: Journal of Social, Cultural and Political Protest 9 (3): 235-51.

Deleuze, Gilles, and Félix Guattari. 1987. A Thousand Plateaus: Capitalism and Schizophrenia. Minneapolis, MN: University of Minnesota Press.

della Porta, Donatella, and Herbert Reiter. 1998. Introduction: The Policing of Protest in Western Democracies. In Policing Protest. The Control of Mass Demonstrations in Western Democracies, eds Donatella della Porta and Herbert Reiter, 132. Minneapolis, MN: University of Minnesota Press.

della Porta, Donatella, and Sidney Tarrow. 2012. Interactive Diffusion. The Coevolution of Police and Protest Behavior with an Application to Transnational Contention. Comparative Political Studies 45 (1): 119-52.

Dießelmann, Anna-Lena. 2015. Ausnahmezustand im Sicherheits- und Krisendiskurs. Eine diskurstheoretische Studie mit Fallanalysen. Siegen: Universitätsverlag Siegen.

Eijkman, Quirine. 2011. Police Technology and Human Rights: A New Quest for Accountability? Journal of Police Studies 20: 195-204.

Feest, Johannes, and Erhard Blankenburg. 1972. Die Definitionsmacht der Polizei. Strategien der Strafverfolgung und soziale Selektion. Studienbücher zur Sozialwissenschaft 1. Düsseldorf: Bertelsmann Univ.-Verl.

Fernandez, Luis A, and Laura Huey. 2009. Is Resistance Futile? Thoughts on Resisting Surveillance. Surveillance \& Society 6 (3): 199-202.

Foucault, Michel. 1979. Discipline and Punish: The Birth of the Prison. New York: Vintage Books.

Freudenschuß, Magdalena. 2015. Paradoxe Dynamik. Aktivismus zwischen Anonymität und Sichtbarkeit. Forschungsjournal Soziale Bewegungen 28 (3): 55-62.

Galdon Clavell, Gemma. 2014. Surveillance by Any Other Name? Understanding Counter-Surveillance as Critical Discourse and Practice. Teknokultura. Revista de Cultura Digital y Movimientos Sociales 11 (2): 329-48.

Gillham, Patrick F., and John A. Noakes. 2007. "More than a March in a Circle": Transgressive Protests and the Limits of Negotiated Management. Mobilization: An International Journal 12: 341-57.

Goldsmith, Andrew. 2010. Policing's New Visibility. British Journal of Criminology 50 (5): 914-34.

Greer, Chris, and Eugene McLaughlin. 2010. We Predict a Riot? Public Order Policing, New Media Environments, and the Rise of the Citizen Journalist. British Journal of Criminology 50 (6): 1041-1059.

Haggerty, Kevin D., and Richard V. Ericson. 2000. The Surveillant Assemblage. British Journal of Sociology 51 (4): $605-22$.

Hellmann, Kai-Uwe. 1996. Systemtheorie und neue soziale Bewegungen. Identitätsprobleme in der Risikogesellschaft. Opladen: Westdeutscher Verlag.

Hempel, Leon, and Eric Töpfer. 2009. The Surveillance Consensus. European Journal of Criminology 6 (2): 157-77.

Hermida, Alberto, and Víctor Hernández-Santaolalla. 2017. Twitter and Video Activism as Tools for Counter-Surveillance: The Case of Social Protests in Spain. Information, Communication \& Society: 1-18.

Hier, Sean P. 2003. Probing the Surveillant Assemblage: On the Dialectics of Surveillance Practices as Processes of Social Control. Surveillance \& Society 1 (3): 399-411.

Hirsch, Joachim. 1986. Der Sicherheitsstaat. Das 'Modell Deutschland', seine Krise und die neuen sozialen Bewegungen. Rev. Reprint. Frankfurt/Main: Athenäum Verlag.

Kääriäinen, Juha, Pekka Isotalus, and Gunnar Thomassen. 2016. Does Public Criticism Erode Trust in the Police? The Case of Jari Aarnio in the Finnish News Media and Its Effects on the Public's Attitudes towards the Police. Journal of Scandinavian Studies in Criminology and Crime Prevention, 1-16.

Kammerer, Dietmar. 2011. Bilder der Überwachung. Frankfurt/Main: Suhrkamp.

Kammerer, Dietmar. 2016. Kampf um die Bilder. Videoüberwachung und Gegenüberwachung von Demonstrationen in Österreich. Juridikum, (4): 527-37.

Knopp and Ullrich. 2016. 'Kampf um die Bilder. Videoüberwachung und Gegenüberwachung von Demonstrationen in Österreich'. Juridikum 4: 527-37.

Knopp, Philipp, and Peter Ullrich. submitted. Abschreckung im Konjunktiv. Macht- und Subjektivierungseffekte von Videoüberwachung auf Demonstrationen.

Knopp, Philipp, und Frederike Müller-Späth. 2017. Protestereignisse und Videoüberwachung in Berlin: Eine ethnografische Studie. IPB Working Papers. Institut für Protest- und Bewegungsforschung. https://protestinstitut.eu/ipb-workingpapers/.

Lamnek, Siegfried. 1998. Gruppendiskussion. Theorie und Praxis. Weinheim: Beltz.

Luhmann, Niklas. 1996. Protest. Systemtheorie und soziale Bewegungen. Frankfurt/Main: Suhrkamp.

Lyon, David. 2001. Surveillance Society: Monitoring Everyday Life. Philadelphia: Open University Press.

Mann, Steve, Jason Nolan, and Barry Wellman. 2003. Sousveillance: Inventing and Using Wearable Computing Devices for Data Collection in Surveillance Environments. Surveillance 1 (3): 331-55.

Marquez, Xavier. 2012. Spaces of Appearance and Spaces of Surveillance. Polity 44 (1): 6-31. 
Marx, Gary T. 1999. What's in a Name? Some Reflections on the Sociology of Anonymity. Information Society 15: 99-112.

Marx, Gary T. 2003. A Tack in the Shoe. Neutralizing and Resisting the New Surveillance. Journal of Social Issues 59 (2): 369 90.

Mathiesen, Thomas. 1997. The Viewer Society. Michel Foucault's Panopticon Revisited. Theoretical Criminology 1 (2): $215-34$. Mayring, Philipp. 2000. Qualitative Inhaltsanalyse. Forum Qualitative Sozialforschung 1 (2): Art. 20.

Monahan, Torin. 2006. Counter-Surveillance as Political Intervention? Social Semiotics 16 (4): 515-34.

Neumayer, Christina, and Gitte Stald. 2014. The Mobile Phone in Street Protest: Texting, Tweeting, Tracking, and Tracing. Mobile Media \& Communication 2 (2): 117-33.

Poster, Mark. 1990. The Mode of Information: Poststructuralism and Social Context. Cambridge, UK: Polity Press.

Ragnedda, Massimo. 2011. Social Control and Surveillance in the Society of Consumers. International Journal of Sociology and Anthropology 3 (6): 180-88.

Reicher, Stephen, Clifford Stott, John Drury, Otto Adang, Patrick Cronin, and Andrew Livingstone. 2007. Knowledge-Based Public Order Policing. Principles and Practice. Policing - A Journal of Policy and Practice 1 (4): 403-15.

Rikspolisstyrelsen, ed. 2013. The Anthology. GODIAC - Good Practice for Dialogue and Communication as Strategic Principles for Policing Political Manifestations in Europe. Uppsala: GODIAC-projektet..

Rucht, Dieter. 2004. The Quadruple A: Media Strategies of Protest Movements since the 1960s. In Cyberprotest: New Media, Citizens and Social Movements, eds Wim van den Donk, Brian D. Loader, Paul G. Nixon, and Dieter Rucht, 25-48. New York: Routledge.

Rucht, Dieter, and Friedhelm Neidhardt. 2002. Towards a "Movement Society?" On the Possibilities of Institutionalizing Social Movements. Social Movement Studies 1 (1): 7-30.

Schaefer, Brian P., and Kevin F. Steinmetz. 2014. Watching the Watchers and McLuhan's Tetrad: The Limits of Cop-Watching in the Internet Age. Surveillance \& Society 12 (4): 502-15.

Schmitt-Beck, Rüdiger. 1990. Über die Bedeutung der Massenmedien für soziale Bewegungen. Kölner Zeitschrift für Soziologie und Sozialpsychologie 42 (4): 642-62.

Scholl, Christian. 2010. Two Sides of a Barricade. (Dis) Order and Summit Protest in Europe. Selbstverlag.

Schreiber, Martina. 2011. Germany. May Day in Berlin. In Managing Collective Violence around Public Events. An International Comparison, eds Otto Mathieu and Joseph Adang, 21-44. Apeldoorn: Politie \& Wetenschap.

Schug, Caroline. 2012. Broadcast Yourself: Eine qualitative Untersuchung zur Darstellung der Polizei bei Großereignissen auf der Internetplattform YouTube und ihrer Wirkung auf die Nutzer. Neue Kriminalpolitik 24 (1): 11-16.

Schug, Caroline, and Joachim Kersten. 2013. Social Media Images of Police Use of Force during Protest Demonstrations. In The Anthology. GODIAC - Good Practice for Dialogue and Communication as Strategic Principles for Policing Political Manifestations in Europe, edited by Rikspolisstyrelsen, 218-25. Uppsala: GODIAC-projektet.

Singelnstein, Tobias. 2014. Körperverletzung im Amt durch Polizisten und die Erledigungspraxis der Staatsanwaltschaften - aus empirischer und strafprozessualer Sicht. Neue Kriminalpolitik 25 (1): 15-27.

Skolnick, Jerome H. 1966. Justice Without Trial. Law Enforcement in Democratic Society. New Orleans, LA: Quid Pro, LLC.

Starr, Amory, Luis A. Fernandez, Randall Amster, Lesley J. Wood, and Manuel J. Caro. 2008. The Impacts of State Surveillance on Political Assembly and Association: A Socio-Legal Analysis. Qualitative Sociology 31 (3): 251-70.

Steven, Elke. 2015. Blockupy. Demonstrationsbeobachtung am 18. März 2015, eds Komitee für Grundrechte und Demokratie e.V. Köln. [accessed July 20, 2017]. http://www.grundrechtekomitee.de/sites/default/files/BerichtBlockupy2015.pdf.

Stott, Clifford. 2009. Crowd Psychology \& Public Order Policing. An Overview of Scientific Theory and Evidence. Submission to the HMIC Policing of Public Protest Review Team.

Strauss, Anselm L., and Juliet M Corbin. 1998. Basics of Qualitative Research. Techniques and Procedures for Developing Grounded Theory. 2nd ed. Thousand Oaks, CA: Sage.

Teune, Simon. 2012. Corridors of Action. Protest Rationalities and the Channeling of Anti-Summit Repertoires. PhD diss., Berlin: Freie Universität Berlin.

Tuma, René. 2017. Videoprofis im Alltag. Die kommunikative Vielfalt der Videoanalyse. Wiesbaden: Springer Fachmedien.

Ullmann, Karen. 2008. Das Ampelsystem. Polizeiliche Gefahrenprognosen während des G8-Gipfels. In Feindbild Demonstrant. Polizeigewalt, Militäreinsatz, Medienmanipulation; der G8-Gipfel aus Sicht des Anwaltlichen Notdienstes, eds Republikanischer Anwältinnen- und Anwälteverein, 33-44. Berlin: Assoziation A.

Ullrich, Peter. 2014. Protest und technische Überwachung. Das Beispiel Videoüberwachung. Forschungsjournal Soziale Bewegungen 27 (4): 40-50.

Ullrich, Peter. 2017. "Normalbürger" versus "Krawalltouristen": Polizeiliche Kategorisierungen von Demonstrationen zwischen Recht und Soziologischem Ermessen. In Empirische Polizeiforschung XX. Polizei und Minderheiten, ed Karlhans Liebl, 61-97. Frankfurt/Main: Verlag für Polizeiwissenschaft.

Ullrich, Peter. 2018a. Researching Police in/under Protest. Police Research as a Journey of Discovery with Obstacles. ipb working papers 1. Berlin: Institut für Protest- und Bewegungsforschung. https://protestinstitut.eu/wp-content/uploads/2018/03/Researching-Police ipb-working-paper 1-18.pdf.

Ullrich, Peter. 2018b. Videoüberwachung von Demonstrationen und die Definitionsmacht der Polizei. Zwischen Objektivitätsfiktion und selektiver Sanktionierung. Technical University Technology Studies Working Papers 2. Berlin: Technische Universität. http://www.ts.tu-berlin.de/fileadmin/i62 tstypo3/TUTS-WP22018 Video\%C3\%BCberwachungVonDemonstrationen.pdf 
Ullrich, and Gina Rosa Wollinger. 2011. A Surveillance Studies Perspective on Protest Policing: The Case of Video Surveillance of Demonstrations in Germany. Interface Journal 3 (1): 13-33.

Ullrich, Peter, Priska Daphi, and Britta Baumgarten. 2014. Protest and Culture. Concepts and Approaches in Social Movement Research: An Introduction. In Conceptualizing Culture in Social Movement Research, eds Britta Baumgarten, Priska Daphi, and Peter Ullrich, 1-20. Basingstoke: Palgrave Macmillan.

von Brackel, Benjamin. 2012. Bitte recht freundlich. Der Freitag, June 6.

Wahlström, Mattias. 2011. The Making of Protest and Protest Policing: Negotiation, Knowledge, Space, and Narrative. Gothenburg: University of Gothenburg.

Wilson, Dean. 2012. Counter-Surveillance: Protest and Policing. Plymouth Law and Criminal Justice Review 4: 33-42.

Wilson, Dean Jonathon, and Tanya Serisier. 2010. Video Activism and the Ambiguities of Counter-Surveillance. Surveillance \& Society 8 (2): 166-80.

Wood, Lesley J. 2014. Crisis and Control. The Militarization of Protest Policing. New York: Pluto Press. 